\title{
Teoria da Ação Comunicativa: considerações sobre interdisciplinaridade na educação profissional
}

\section{Theory of communicative action: considerations on interdisciplinarity in vocational education}

\author{
Deise Aparecida Peralta ${ }^{1}$ \\ Harryson Junio Lessa Gonçalves ${ }^{2}$
}

\begin{abstract}
Resumo
Este ensaio teórico tem como objetivo apresentar algumas considerações, segundo os princípios habermasianos da Teoria da Ação Comunicativa, sobre ensino de matemática em cursos de educação profissional no que se refere a aspectos e práticas interdisciplinares. A aproximação da problemática foi feita por meio de análises de prescrições curriculares de cursos de Educação Profissional Técnica de Nível Médio. Observa-se que o pressuposto de abordagem interdisciplinar da matemática é essencial para a formação dos profissionais técnicos, contudo constata-se visão funcionalista de interdisciplinaridade, eminentemente pautada em racionalidade técnica, onde as tentativas de articulações entre os diversos componentes curriculares prescindem de fomento a atividade coletiva pressuposto basilar da racionalidade comunicativa.
\end{abstract}

Palavras-chave: Interdisciplinaridade; Educação Profissional; Currículo de Matemática, Teoria da Ação Comunicativa.

\begin{abstract}
This article aims to present some considerations, according to the principles of Habermas Theory of Communicative Action on teaching mathematics in professional education courses with regard to the aspects and interdisciplinary practices. The approach of the issue was made through analysis of curriculum prescriptions of Vocational Education High School Technical. It is observed that the interdisciplinary approach assumption of mathematics is essential for the formation of technical professionals, however notes to the functionalist view of interdisciplinarity, eminently guided by technical rationality, where attempts to joints between the various curricular components dispenses courses fostering collective activity basic assumption of rationality Communicative.
\end{abstract}

Keywords: Interdisciplinarity; Vocational Education; Mathematics Curriculum; Theory of Communicative Action.

\footnotetext{
${ }^{1}$ Doutorado em Educação Para a Ciência pela Universidade Estadual Paulista "Júlio de Mesquita Filho" (UNESP). Professora na UNESP no Departamento de Matemática da Faculdade de Engenharia - Câmpus de Ilha Solteira - e no Programa de Pós-Graduação em Ensino e Processos Formativos (UNESP - Câmpi Ilha Solteira, Jaboticabal e São José do Rio Preto). Email: deise@mat.feis.unesp.br.

${ }^{2}$ Doutor em Educação Matemática pela Pontifícia Universidade Católica de São Paulo (PUC-SP). Professor na UNESP no Departamento de Biologia e Zootecnia da Faculdade de Engenharia - Câmpus de Ilha Solteira -, no Programa de PósGraduação em Educação para a Ciência da Faculdade de Ciências - Câmpus de Bauru - e no Programa de PósGraduação em Ensino e Processos Formativos (UNESP - Câmpi de Ilha Solteira, Jaboticabal e São José do Rio Preto). Email: harryson@bio.feis.unesp.br.
} 


\section{Introdução}

Pensadores críticos da sociedade têm, desde os anos finais da década de 1960, questionado a submissão da educação aos imperativos do sistema produtivo e a consequente degradação da função emancipatória da educação (Mühl, 2003). Autores tais como Horkheimer (1980) e Adorno (1996), já evidenciavam a perspectiva técnica e a fundamentação sistêmica da racionalidade humana promovidas pelo avanço da indústria e do capitalismo na Europa, na medida em que a fundamentação crítica da racionalidade se permitiu encobrir-se de uma forma técnica e imediatista de pensar e agir (Horkheimer \& Adorno, 1985). Evidentemente, condições materiais de existência devem ser consideradas e as pessoas precisam estar preparadas para a produção e o consumo de conhecimento técnicocientífico necessário ao mundo do trabalho, porém, é forçoso atentar para as elaborações simbólicas que também são essenciais à vida. O predomínio de certo tipo de racionalidade na sociedade moderna, a racionalidade instrumental, obscurece a sustentação ética e política da produção teórica, porém, é necessário que a educação, principalmente a modalidade profissional, recupere essas dimensões.

\section{A crise da racionalidade}

Para alguns (Mühl, 1999; Prestes, 1995; Sgró, 2007; Tedesco, 2004; Teodoro, 2003), o que se passa hoje com relação à educação não é resultado de causas setoriais, nacionais ou estratégicas, mas tem origens mais profundas, relacionadas a uma determinada visão de mundo. Trata-se, de fato, da crise da própria modernidade. Muito embora a educação, em diferentes tempos e lugares, tenha apresentado diversas nuances e funções, com o Iluminismo passou a ser entendida como ferramenta para a emancipação humana, sendo considerada indispensável para o desenvolvimento da racionalidade e da liberdade, de tal maneira que a escola vem desempenhando papel vital na construção da modernidade. Assim, a crise, que coloca sob suspeita a própria capacidade da razão em fundamentar e orientar um projeto histórico acarreta também uma profunda crise no sistema educacional. Crise esta, facilmente, transposta ao universo da formação profissional técnica.

Mas afinal, o que podemos entender por racionalidade? Buscando na obra do filósofo e sociólogo alemão Jurgen Habermas, expoente do que se considera a segunda geração da Escola de Frankfurt, fundamentos para uma explanação sobre esse questionamento é possível encontrar, claramente, uma via pragmática, onde "a racionalidade tem menos a ver com o conhecimento ou com a aquisição de conhecimento que com a forma em que os sujeitos capazes de linguagem e de ação fazem uso do conhecimento" (Habermas, 2001, p. 24).

Nesse sentido, ao problematizarmos acerca de racionalidade aceitamos que opiniões podem ser expostas, explicitamente, em forma de enunciados, e nós só sabemos algo a respeito de algo se nós sabemos ao mesmo tempo porque os julgamentos correspondentes são aceitos. A racionalidade de uma emissão ou manifestação depende assim da fiabilidade do saber que encarnam, logo, na sua susceptibilidade de crítica ou de fundamentação. Para que 
uma opinião seja dita racional, basta que ela seja aceita por boas razões no interior de um contexto de justificação, ou seja, a racionalidade de um julgamento não implica sua verdade, mas apenas sua aceitabilidade fundada dentro de um contexto dado (Habermas, 2001).

Mas a proposta de reduzir a racionalidade de uma emissão ou manifestação a sua susceptibilidade de crítica ou fundamentação parece incorrer em certa abstração e restrição. Ou seja: aparenta ser pouco descritiva e objetiva essa caracterização de racionalidade? O pensamento habermasiano sinaliza que não se, convertendo o questionamento do pressuposto ontológico de um mundo objetivo para um pressuposto fenomenológico, a objetividade passa a ser uma questão de reconhecimento por uma comunidade, cujo contexto comum é assegurado pela prática comunicativa. A ideia de verdade só pode ser aceita por referência ao desempenho discursivo de pretensões de validez (Habermas, 1984). Por isso, Habermas (2001) sustenta uma razão imanente à prática comunicativa, que abarca um espectro mais amplo que aquele que vincula o 'racional' às pretensões de verdade ou de eficiência.

A racionalidade defendida por Habermas (2001) emerge como via alternativa à crise da racionalidade de caráter instrumental impregnada na modernidade. Os teóricos da primeira geração da Escola de Frankfurt advertiram sobre o que se constitui a "crise da racionalidade da modernidade" que pode ser resumidas nas interpretações de Longhi (2005) da seguinte maneira: A modernidade privilegiou um tipo de racionalidade centrada na concretização de seus fins voltada apenas na dominação e controle dos mundos objetivo e social e a principal consequência dessa dominação é a adoção de um modelo de razão humana segundo o qual "o que pensa ou o que diz um indivíduo racional ilustrado também pensam e fazem todos os demais homens nas mesmas condições.” (Longhi, 2005, p. 8).

A problemática da disfunção da racionalidade com respeito a fins no processo de formação da sociedade, com profunda influência no modelo de formação para o trabalho, foi e é muito discutida na obra sistematizada por Jürgen Habermas.

A ação racional com respeito a fins é, segundo sua própria estrutura, exercícios de controle. Por conseguinte, a racionalização das relações vitais segundo critérios dessa racionalidade equivale à institucionalização de uma dominação que, enquanto política, se torna irreconhecível: ação razão técnica de um Sistema social de ação racional dirigida a fins não abandona o seu conteúdo político. (Habermas, 1968, p. 46)

A vista desse cenário, é importante compreender as racionalidades que fundamentam, direta ou indiretamente, a efetivação de políticas curriculares que se relacionam diretamente com o ensino de matemática na educação profissional e sua relação com prática interdisciplinares.

Ações docentes, incluindo as referentes à formação profissional, deveriam ser pautadas por critérios que não apenas aqueles oriundos da racionalidade instrumental, que já deu indícios de sua insuficiência pela não realização das metas previstas de libertação do homem, diante de todas as formas de tirania e obscurantismo. O pensamento de Habermas pode nos ajudar a compreender as políticas educacionais e o papel dos cidadãos, bem como apontar possibilidades de resistências aos imperativos sistêmicos no que diz respeito à Zetetiké, Campinas, SP, v.24, n.3, set./dez.2016, p.378-394 
constituição do que se seria o ensino de matemática e sua relação com a "preparação para o mundo do trabalho".

\section{A Teoria da Ação Comunicativa}

Jürgen Habermas propõe uma crítica à sociedade. Para tanto desenvolve uma teoria comunicacional defendendo que a comunicação entre os interlocutores sociais seja analisada segundo as relações que as subjazem. As ações de Habermas, inspirado pela Ética comunicativa de Karl Otto Apel, são voltadas à defesa do potencial emancipatório da razão. Nesse sentido, Adorno e Horkheimer, marcados pela Segunda Guerra Mundial, consideravam que há um vínculo entre conhecimento racional e dominação, o que determinaria a falência dos ideais de um projeto moderno de emancipação. Ao pretender a recuperação do conteúdo emancipatório da razão, Habermas dá evidências de estar preocupado com o restabelecimento dos vínculos entre socialismo e democracia.

Habermas (1987) descreve quatro tipos de ações: a) a ação teleológica, em que um ator escolhe, entre diferentes alternativas, os melhores meios para conseguir um fim no mundo objetivo; b) a ação regulada por normas, em que os membros de um grupo social orientam suas ações segundo umas normas comuns do mundo social; c) a ação dramatúrgica, em que as pessoas se comportam como se as outras fossem seu público, havendo a necessidade de "cenificação", de construção de certa imagem; d) a Ação Comunicativa, na qual a interação ocorreria entre sujeitos capazes de linguagem e de ação, com fins de Entendimento.

Com relação à coordenação de ações entre sujeitos de um Discurso num processo de interação social, Habermas admite duas formas de interação: estratégica e comunicativa. Nesse processo as relações entre ação e Discurso podem evoluir de maneiras distintas dependendo da forma como as ações são orientadas: se objetivando unicamente o êxito (ação estratégica) ou objetivando o entendimento (ação comunicativa) (Habermas, 2002). Dentro dessa lógica, Habermas (1968) apresenta a racionalidade comunicativa em oposição à racionalidade instrumental. A primeira surge como norteadora às interações mediadas simbolicamente, não excluindo a possibilidade de uma racionalidade teleológica. A segunda pode assumir a forma de racionalidade estratégica quando orienta as ações dos sujeitos no mundo no que diz a organização dos meios de interação ou à escolha de possibilidades:

A ação instrumental orienta-se por regras técnicas que se apóiam no saber empírico. Estas regras implicam em cada caso prognoses sobre eventos observáveis, físicos ou sociais: tais prognoses podem se revelar verdadeiras ou falsas. O comportamento da escolha racional orienta-se por estratégias que se baseiam num saber analítico. Implicam deduções de regras de preferências (Sistemas de valores) e máximas gerais: estas proposições estão deduzidas de um modo correto ou falso (Habermas, 1968, p. 57).

Em síntese, a ação estratégica faz uso da linguagem apenas como meio de transmissão de informações buscando influenciar os outros sujeitos do Discurso de maneira a impor posições; ao passo que a ação comunicativa eleva a linguagem ao status de fonte de interação 
social com potencial consensual dos processos linguísticos visando à promoção de entendimento.

Dentro da perspectiva da Teoria Crítica, contrapondo-se à razão instrumental, Habermas (2001, 2002, 2003) desenvolve a Teoria da Ação, que discute uma racionalidade da comunicação. A ação comunicativa é orientada para o entendimento e não para a manipulação e encontra-se implícita nas relações sociais, contrastando com a racionalidade instrumental dirigida à produção de condições materiais de vida, permitindo a reprodução da sociedade. A ação comunicativa objetiva a ausência de assimetrias entre os sujeitos que pretendam se entender. Caso o potencial comunicativo não se realize surge a necessidade de emancipação.

Numa interação, um sujeito não pode pretender conseguir entendimento com outro e exercer influência sobre o mesmo, pois não pode ser intersubjetivamente, considerado um acordo, ações que violam condições sob as quais as forças ilocutórias despertam convicções e originam 'ligações' (Habermas, 2002). A emancipação, portanto, só é possível no contexto de interações mediadas linguisticamente que visam o entendimento. $\mathrm{O}$ entendimento buscado com relação à verdade, à justiça e à veracidade, que fundamentam as ações de cada um dos interlocutores, é intersubjetivamente compartilhado, apresentando-se na forma de consensos obtidos discursivamente e sem impedimentos.

Pensando razão pode alcançar tanto o mundo objetivo, quanto o social e o subjetivo (relacionado intimamente ao mundo da vida). Sendo assim, educação profissional, segundo um agir comunicativo, só pode ser pautada em formação para se estar em interação com o mundo do trabalho, numa relação dialógica e simétrica com vistas à emancipação, muito mais que pela formação para se empregar a serviço do mundo do trabalho. A matemática dentro deste paradigma se constitui em prática que relaciona conhecimento tanto do mundo objetivo (de domínio maior do sistema) - integrando conhecimentos científicos específicos constituídos historicamente pela área, quanto o social e o subjetivo (relacionado intimamente ao mundo da vida) - integrando conhecimentos que subsidiarão argumentos e orientarão escolhas pessoais acerca da vida e da profissão. Isto posto, entendendo que essa prática, compartilhada entre quem ensina e quem aprender matemática, busque o entendimento, por meio de consenso, perseguindo os ideais de emancipação.

\section{O Sistema e o Mundo da Vida}

Para Habermas duas esferas coexistem na sociedade: o sistema e o mundo da vida. $\mathrm{O}$ sistema refere-se à reprodução material, em consonância com uma lógica instrumental (adequação de meios a fins), orientando relações hierárquicas (poder político) e de intercâmbio (economia). O mundo da vida é a esfera de reprodução simbólica, da linguagem, das redes de significados que constitui determinada visão de mundo, sejam eles referentes aos fatos objetivos, às normas sociais ou aos conteúdos subjetivos.

Existe uma conexão interna entre a teoria da racionalidade e a teoria da sociedade. 
Nesse contexto, cultura é definida como "reserva de conhecimento à qual os participantes na comunicação, ao se entenderem uns com os outros, vão buscar suas interpretações" (Habermas, 2001, p.139). O aumento da complexidade do sistema social dificulta a obtenção de entendimento, o que possibilita a existência e a manutenção de meios de controle independentes da linguagem: o dinheiro, instrumento do mercado e o poder, instrumento do Estado. Habermas afirma que há um sempre contínuo processo de colonização do mundo da vida pelo sistema, bem como uma crescente instrumentalização desencadeada pela modernidade.

Segundo Gonçalves (1999), a colonização representa a dominação da racionalidade instrumental em dimensões que deveriam privilegiar a racionalidade comunicativa. A inserção da racionalidade instrumental na ação humana interativa, ao produzir um esvaziamento da ação comunicativa e ao reduzi-la à sua própria estrutura de ação, gera, no homem contemporâneo individualismo, isolamento, competição, que estão na base dos problemas sociais.

Habermas considera que processo de racionalização sistêmica é fundamental para o desenvolvimento da humanidade, mas "o progresso e a emancipação humana não dependem da evolução sistêmica e, sim, da ampliação da racionalidade comunicativa e da reflexibilidade dela decorrente" (Mühl 1999, p. 165), ou seja, “ racionalidade sistêmica não pode impor-se e invadir a esfera do mundo da vida, mas deve permanecer restrita à sua dimensão específica, deixando que o mundo da vida, que é de fato a base sustentadora de toda a realidade social, mantenha-se regido pela racionalidade comunicativa" (p. 167).

Diante disso é possível admitir que uma das maiores contribuições de Habermas esteja em pretender o fim da arbitrariedade e da coerção nas questões que circundam toda a comunicação social, propondo uma participação mais ativa e igualitária de todos os agentes. Sendo assim, educação profissional não pode ser entendida como modalidade de educação preocupada com formação humana se prescindir das questões relativas ao mundo da vida, privilegiando aspectos dos imperativos sistêmicos.

É possível afirmar que haja um aumento de subordinação das políticas educativas aos imperativos das políticas econômicas e nesse caso, adentram às instituições de ensino profissional interesses mercadológicos desconsiderando que processos formativo são dimensões da constituição histórica do indivíduo (Medeiros, 2005). Neste sentido, corremos o risco de formar sujeitos que executam trabalho e não sujeitos que interagem com o mundo do trabalho. Sendo assim temos uma relação de colonização, onde a finalidade da formação é a capacitação tendo sempre justificação para os meios, e não de busca ao ideal da emancipação, onde a própria formação já seja entendida como interação transformadora no mundo e nas relações e trabalho.

A racionalidade com respeito a fins não é a única forma de manifestação da razão, ao contrário, esta - a razão - se evidencia primariamente na forma de racionalidade comunicativa, que pode ser mobilizada igualmente para uma formação de caráter crítico e 
emancipatório e para uma participação política mais efetiva dos sujeitos.

Uma modalidade de educação profissional pautada no conceito de emancipação fundamenta a busca de formação, com vistas a desenvolver entendimento, por meio da razão comunicativa, pois existem fenômenos que independem do controle do sistema, sendo este incapaz de controlar de um todo o mundo da vida. A capacidade de entendimento conserva a possibilidade de contra controlar o sistema, impedindo que o mundo da vida seja controlado de modo absoluto pela ideologia sistêmica.

\section{Ação Comunicativa X Ação Estratégica: Razão Comunicativa X Razão Instrumental}

Habermas acredita que haja dominação da racionalidade técnica na estrutura da modernidade e defende a necessidade de refletir sobre o conceito de racionalidade. Para tanto, se lança a compreender como e porque ela foi invadida por modos de agir de caráter técnico e, então, apresentar caminhos pelos quais entende como possível o reestabelecimento do potencial emancipatório da racionalidade.

E aqui a ideia de paradigma da dominação se traduz como aquele que age isoladamente, ou seja, procurando segregar as pessoas e torná-las meio para um fim prédeterminado tecnicamente. Essa ideia faz parte do corpo teórico entendido como racionalidade técnica, pois encobre com ar de neutralidade os objetivos da dominação.

Na medida em que os atores estão exclusivamente orientados para o sucesso, isto é, para as consequências do seu agir, eles tentam alcançar os objetivos de sua ação influindo externamente, por meio de armas ou bens, ameaças ou seduções, sobre a definição da situação ou sobre as decisões ou motivos de seus adversários. A coordenação das ações de sujeitos que se relacionam dessa maneira, isto é, estrategicamente, depende da maneira como se entrosam os cálculos de ganho egocêntricos. O grau de cooperação e estabilidade resulta então das faixas de interesses dos participantes. Ao contrário, falo em agir comunicativo quando os atores tratam de harmonizar internamente seus planos de ação e de só perseguir suas respectivas metas sob a condição de um acordo existente ou a se negociar sobre a situação e as consequências esperadas (Habermas, 2003, p. 164-165).

Nesse sentido, o autor diferencia os tipos de ação de um sujeito ou de um grupo de pessoas com base na forma como elas são voltadas a um entendimento (Habermas, 2003), ou a um processo de convencimento ou dominação de outrem por meio do uso da fala. Nessa compreensão, as ações exercidas carregam consigo marcas de sua racionalidade, que pode ser comunicativa ou estratégica.

A razão instrumental orienta-se por regras técnicas que se apoiam no saber empírico. Estas regras implicam em cada caso prognoses sobre eventos observáveis, físicos ou sociais: tais prognoses podem se revelar verdadeiras ou falsas. O comportamento da escolha racional orienta-se por estratégias que se baseiam num saber analítico. Implicam deduções de regras de preferências (sistemas de valores) e máximas gerais: estas proposições estão deduzidas de um modo correto ou falso (Habermas, 1968, p. 57). 
Em síntese, a ação estratégica faz uso da linguagem apenas como meio de transmissão de informações buscando influenciar os outros sujeitos do discurso de maneira a impor posições ou com o objetivo de atingir um êxito na comunicação, independente das compreensões que os interlocutores; ao passo que a ação comunicativa eleva a linguagem ao status de fonte de interação social com potencial consensual dos processos linguísticos visando à promoção de entendimento.

A ação comunicativa deve ser orientada para o entendimento e não para a manipulação e encontra-se implícita nas relações sociais, contrastando com a racionalidade instrumental dirigida à produção de condições materiais de vida, permitindo a reprodução da sociedade. Portanto, uma proposta curricular para formação profissional, dentro dessa perspectiva, deveria conter orientações que estimulassem a interação livre de assimetrias e coerções entre as áreas do conhecimento e entre as pessoas envolvidas; uma postura de troca e diálogos constantes sem formas de manipulações; a criação de espaços coletivos voltados ao desenvolvimento de entendimento, consensos e ideais de emancipação.

\section{Educação Profissional e a Racionalidade das Prescrições Curriculares}

Em diferentes documentos oficiais, identificamos a proposta de articulação entre as áreas do conhecimento como um eixo norteador da educação profissional, cuja modalidade de ensino mesmo sendo responsável pela formação de técnicos não, necessariamente, precisa ser impregnada somente por uma racionalidade eminente instrumental (Horkheimer, 1976).

Neste sentido educação profissional aqui é entendida, em uma espécie de desdobramento dialético, como etapa de formação onde o indivíduo deveria buscar sua autonomia e a sua emancipação com a oportunidade de atuar no mundo mediante uma atividade laboral. Contudo, por vezes pode ocorrer que a educação profissional idealizada por uma razão onipotente, dominadora da natureza, que busca submeter a natureza e a sociedade à objetividade de uma determinada racionalidade, não atinja o fim emancipador. Neste caso, pode transformar-se em mera abstração, mero instrumento formal de recrutamento de massas para o setor produtivo mercadológico.

Acreditamos que a forma como o ensino de conteúdos curriculares se apresenta nos cursos de educação profissional pode ser legitimadora de prática de pilhagem - prática do trabalho para o capital, da exploração dos homens para o capital (Matos, 1989) ou pode ser a tentativa de ruptura com dimensões do aparato produtivo e das mercadorias que se impõem, ao sistema social, como um todo que se impõe na eterna contradição entre produtividade e destruição, dominação e progresso, prazer e infelicidade. Uma forma de tentativa de ruptura é justamente a interdisciplinaridade que propõe o diálogo nas instituições educacionais, a comunicação entre os agentes das práticas de ensino, a comunhão de objetivos individuais com vistas a coletividade, a superação da racionalidade meramente instrumental pela racionalidade comunicativa (Habermas, 2002). 
As Diretrizes Curriculares Nacionais para o Ensino Médio (Brasil, 2012a) apontam que o Ensino Médio deve promover a integração de conhecimentos na perspectiva da interdisciplinaridade e da contextualização; todavia, não encontramos nestes documentos parâmetros que orientem os professores acerca de posturas a serem adotadas quando o objetivo é a efetivação de práticas interdisciplinares.

As Diretrizes Curriculares Nacionais para a para a Educação Profissional Técnica de Nível Médio (Brasil, 2012b) aponta a interdisciplinaridade como um dos princípios norteadores da organização e desenvolvimento curricular. No entanto, não há, explicitamente, menções onde se possa entender que integração e/ou articulação da Educação Profissional com o Ensino Médio, exigida pelos currículos prescritos, seja suficiente para garantir a abordagem interdisciplinar desses currículos, privilegiando o devido diálogo e a interação comunicativa entre os agentes educativos, rompendo com a racionalidade técnica. Não sendo possível ainda, pelo texto dos documentos, entender os conceitos (de interdisciplinaridade, de integração e de articulação) defendidos e como estes de efetivariam na prática. A falta de preocupação com o entendimento dos sujeitos envolvidos nos processos de implementação dos currículos, aparentemente, reflete um caráter de razão instrumental.

Os Parâmetros Curriculares Nacionais de Ensino Médio tomam a interdisciplinaridade e a contextualização como ponto de partida à necessidade de superação de práticas pedagógicas descontextualizadas e compartimentadas, considerando-as como eixos viabilizadores da transposição didática do conhecimento no Ensino Médio, visando à ressignificação dos saberes escolares em atendimento às demandas da consolidação do estado democrático, das novas tecnologias e das mudanças na produção de bens, serviços e conhecimentos, possibilitando a integração do aluno ao mundo contemporâneo nas dimensões fundamentais da cidadania e do trabalho.

Os documentos não fazem referências a conceito de interdisciplinaridade, se é que algum fora adotada. Sendo assim, não há indicações de fundamentos acerca de como concretizar práticas interdisciplinares no desenvolvimento curricular. Os documentos mencionam e prescrevem interdisciplinaridade como critério central de adoção de práticas, mas não orientam posturas que promovam o diálogo e um agir comunicativo nas instituições escolares. Assim o sendo, não há compromissos e seguranças oficiais com sua implementação.

A análise dos documentos que regularam a implantação dos currículos de ensino médio, com ou sem a modalidade de ensino profissional, evidencia a racionalidade eminentemente instrumental, pautada numa comunicação meramente estratégica, cujas ações não privilegiam práticas de entendimento acerca do conceito de interdisciplinaridade. As ações de implantação de diretrizes curriculares para Educação Profissional de Nível Técnico carecem de fundamentações a partir da compreensão do processo de esclarecimento enquanto processo de emancipação. As ações deveriam recorrer ao entendimento mútuo como meio para se obter um consenso. Este consenso, ao alcançar um nível de fundamento ético, desempenha um papel forte na organização social, determinando certos comportamentos no 
nível da ação e formação de todos os concernidos. $O$ ato de chegar a um entendimento deveria ser entendido, pelas autoridades representativas de desenvolvimento e implantação curricular como ato pedagógico de geração de uma consciência de libertação social, na medida em que todos os integrantes do processo deveriam estar conscientes das consequências e vantagens do ato coletivo de chegar a um entendimento.

De outra forma, a educação, que sempre foi entendida como instrumento de humanização, tornar-se-ia em nossa época um instrumento de conversão de conhecimentos e bens culturais em mercadorias de desejo, transcendendo o mundo dos fatos, ganhando significados de tal forma que não consumiríamos mais saber, mas sim signos de prestígio, símbolos de poder, status e pertencimento; onde os indivíduos então buscariam conhecimentos para se venderem como objetos no mercado de trabalho. Porém, não é possível encontrar nos referidos documentos a presença de elementos que caracterizem orientações à concretização de práticas interdisciplinares e nem a preocupação com a necessidade de ações comunicativas voltadas aos entendimentos dos envolvidos.

O pressuposto da abordagem interdisciplinar para o ensino de matemática, desejável para a formação dos profissionais técnicos, nas prescrições curriculares é disposto de forma funcionalista com caráter, eminentemente pautado em racionalidade técnica, onde as tentativas de articulações entre os diversos componentes curriculares prescindem de fomento a atividades coletivas - pressuposto basilar da racionalidade comunicativa.

\section{Interdisciplinaridade e ensino de matemática}

Segundo Ubiratan D'Ambrosio, "as disciplinas dão origem a métodos específicos para conhecer objetos de estudo bem definidos. Os métodos e os resultados assim obtidos, que se referem a questionamentos claramente identificados, constituem um corpo nomeado de conhecimento" (D'Ambrosio, 2005, p. 103). Falar em interdisciplinaridade é aludir à integração dessas disciplinas; embora entendendo disciplina como sinônimo de ciência, o termo é mais empregado para designar o ensino de uma dada ciência.

Em Japiassu (1976), a interdisciplinaridade caracteriza-se pela intensidade das trocas entre especialistas e pelo grau de real integração das disciplinas no interior de um mesmo projeto de pesquisa. Ou seja, torna-se possível a complementaridade dos conceitos, métodos, dos axiomas e das estruturas sobre as quais se fundam as diversas práticas científicas.

De acordo com Machado (2000), a interdisciplinaridade tem sido uma palavra-chave na discussão da organização do trabalho acadêmico e escolar, pois supera uma fragmentação crescente dos objetos do conhecimento nas diversas áreas, gerando uma visão de conjunto, e facilita para o processo de ensino-aprendizagem o enquadramento de fenômenos que ocorrem fora da escola, que não se contextualizam no âmbito de uma única disciplina.

Pires (2004) considera que a inserção da matemática no currículo deve superar o 'binômio máquina e produtividade' e afirma que a organização do currículo escolar tradicional, a partir da justaposição das disciplinas, sem nenhum processo de penetração 
mútua, é responsável por uma formação fragmentada, baseada na fragmentação e no esfacelamento do saber.

A abordagem interdisciplinar, em contrapartida, junto a uma postura crítica e a um questionamento constante do saber, traria possibilidades de um enriquecimento por meio de novos enfoques, ou da combinação de perspectivas diferentes, incentivando a busca de caminhos alternativos que não apenas aqueles dos saberes já adquiridos, instituídos e institucionalizados (Pires, 2004, p. 33).

Para Fazenda (2008), pensar a interdisciplinaridade como junção de disciplinas é pensar o currículo apenas na formação de sua grade, porém, ao se definir interdisciplinaridade como atitude de ousadia e busca perante o conhecimento, cabe pensar aspectos que envolvem a cultura do lugar onde os professores se formam. Desse modo, somente torna-se possível falar sobre o professor e sua formação quando ampliamos a análise do campo conceitual da interdisciplinaridade, surgindo, aí, a possibilidade de explicitação de seu espectro: (i) Epistemológico - Para que quero formar este ser? (ii) Ontológico - Que ser queremos formar? (iii) Praxeológico - Quais os valores implícitos quero formar neste ser?

Assim, a interdisciplinaridade é percebida por especialistas como a interação necessária entre as diversas disciplinas no processo de organização e desenvolvimento curricular, a partir de uma análise crítica da realidade e da percepção do papel que o educador tem nesta realidade (Gonçalves, Dias \& Peralta, 2015). Essa interação pode ir da simples comunicação de ideias à integração mútua de conceitos diretores da epistemologia, da terminologia, da metodologia, dos procedimentos, dos dados e da organização referentes ao ensino e à pesquisa.

Apesar da utilização indiscriminada do termo, muitas vezes empregado de maneira acrítica, há a possibilidade do consenso em relação à defesa da interdisciplinaridade ser considerada um dos eixos centrais de um currículo integrado, contudo uma perspectiva crítica deve ser considerada para se evitar banalizações e práticas pedagógicas frágeis que pouco contribua para o processo emancipatório do sujeito (Gonçalves, Dias \& Peralta, 2015).

Em publicações mais recentes, autores que tratam sobre interdisciplinaridade, seja sob o enfoque epistemológico ou pedagógico, continuam a negar o caráter de junção de disciplinas, de prática formatada em grade curricular e, reiteradamente, endossar o caráter de movimento para o diálogo, para a postura integradora (Thiesen, 2008; Tomaz \& David, 2011; Tavares, 2014; Fazenda, 2013; Fazenda, Tavares \& Godoy, 2015; Gentile, 2015, Mateus, 2016). No entanto, Fernandes (2015) reflete sobre os desafios para a efetivação de um projeto interdisciplinar na contemporaneidade e afirma que, atualmente, em consequência do paradigma da modernidade em que estamos imersos, "a interdisciplinaridade, compreendida como integração formal e burocrática das disciplinas em áreas do conhecimento, vem assumindo um caráter instrumental e metodológico nas diversas orientações curriculares existentes." (p. 51).

Terradas (2011), em pesquisa com professores de matemática, ressalta que apesar dos participantes defenderem a interdisciplinaridade como prática desejável no ensino deste 
componente curricular, há entre eles o apego à 'segurança' do modelo de transmissão de conhecimento pelo especialista que garante o 'rigor' aos conceitos e procedimentos da Matemática.

Gonçalves e Pires (2014) analisaram possibilidades, perspectivas e desafios para o ensino de matemática na organização e desenvolvimento curricular da Educação Profissional Técnica de Nível Médio, constatando que professores de matemática evitam adentrar interdisciplinarmente em temas específicos das áreas técnicas devido à insegurança diante dos temas.

Habermas (2001), dentro de uma macro visão aposta numa nova racionalidade a partir do encontro entre filosofia, ciência e mundo da vida, para se contrapor à razão instrumental que domina a sociedade moderna. Na verdade, ver-se-á, dentro de uma concepção habermasiana, que a reivindicação interdisciplinar ora se apresenta como panaceia epistemológica, invocada para curar todos os males que afetam a consciência científica moderna; por vezes se fala dela com um ceticismo radical; por vezes, como uma fatalidade própria do avanço técnico e científico, que de acordo com um Agir Comunicativo só pode ser rompido por meio de entendimento entre os atores envolvidos.

Desta forma, numa perspectiva da ação comunicativa (Habermas, 2001), interdisciplinaridade no ensino de matemática pode ser entendida como uma atitude voltada ao diálogo e ao entendimento, com finalidade de estabelecimento de consensos dentro dos ideais de emancipação dos envolvidos, frente a necessidades sociais e científicas concretas de se aprender os conteúdos desse componente curricular. Assim, consistindo não apenas na procura de correlação, entre objetos do mundo subjetivo e a coleção de vereditos particulares enunciados a partir da especialidade que configura a matemática como área do conhecimento, que não pode ser reduzida à simples justaposição, mas algo a ser construído na coletividade.

Assim, a expressão currículo integrado, por vezes presentes nas prescrições curriculares para ensino técnico e profissional, deveria ser entendida como compreensão global do conhecimento e como a promoção de maiores parcelas de práticas interdisciplinares na construção curricular, visando sempre ações coletivas. Esta integração ressaltaria a unidade, que deve existir entre a matemática e as outras disciplinas, ao passo que potencializaria a diversidade da coletividade nas formas de se relacionar com $o$ conhecimento. Aspecto esse fundamental ao pesarmos em formar para as relações com o mundo do trabalho, rompendo com a razão moderna instrumental disseminada.

Mais do que definir um conceito, julgamos importante, para subsidiar as discussões sobre como o ensino de matemática tem ocorrido em cursos de Educação Profissional, no que se refere a aspectos e práticas interdisciplinares, considerar as controvérsias e a pluralidade de sentido de que se reveste o termo, e as possibilidades de entendimento pautadas na razão comunicativa que cada interpretação desvenda para a prática pedagógica. 


\section{Educação Profissional, Ação Comunicativa e Interdisciplinaridade no Ensino de Matemática}

Ao questionarmos o paradigma da razão instrumental como padrão de racionalização, usado em diretrizes curriculares, introduzindo o conceito de razão comunicativa de Habermas, fazemos a defesa de um salto paradigmático com profundas implicações para as teorias de currículo e para educação profissional. Se, como ele aponta, no âmbito do mundo da vida, onde ocorrem os processos cruciais de produção e transmissão cultural, de socialização e de formação da personalidade individual, a ação deve, necessariamente, ser dirigida por processos comunicativos de busca do entendimento e não através de meios autorregulados, com a Educação Profissional isto significa a necessidade de mudanças profundas na forma de concepção desta área, mudanças estas que implicam na introdução de mecanismos de decisão que levem em conta a participação, com direito a vez e voz, de lodos aqueles que sofrerão os efeitos desta ação.

Ainda que as Diretrizes Curriculares para Educação Profissional Técnica de Nível Médio (Brasil, 2012b) e as Diretrizes Curriculares Nacionais para o Ensino Médio (Brasil, 2012a) estejam evidentemente atrelados a complexas instâncias sistêmicas, dentre elas, as de caráter político e governamental e o aumento da complexidade do sistema social dificulta a obtenção de entendimento e reforça a manutenção de meios de controle independentes da linguagem - sendo previsível a presença da racionalidade técnica em sua redação- o discurso da interdisciplinaridade está presente. Tal presença deveria dar visibilidade a processos alternativos à devastadora instrumentalização desencadeada pela modernidade. Prescrições curriculares deveriam assegurar que racionalidade instrumental não imperasse em dimensões que deveriam privilegiar a racionalidade comunicativa. Interdisciplinaridade não se concretiza no individualismo, no isolamento, na competição. Ensino de matemática com abordagem interdisciplinar precisa estar ancorado em princípios que escapam à racionalização sistêmica.

Prescrição curricular parece não se concretizar, como condição suficiente, para assegurar aspectos interdisciplinares no tocante à educação profissional, enquanto essa se mantiver organizada sobre a lógica de saberes disciplinares como fins e não meios de uma formação. O ensino de matemática neste contexto tem o papel de ferramenta que instrumentaliza, instrui, mas não forma para a totalidade de possibilidades que a matemática, enquanto prática social, pode oferecer para as relações com o mundo do trabalho.

Sob essa lógica o resultado dar-se-á desta forma: um profissional formado para atuar em contextos específicos, que usa a matemática para resolver problemas específicos, mas sem condições de compreensão e problematização dos processos históricos, científicos, culturais e políticos que, interagindo, constituem a realidade social contemporânea. O conhecimento especializado é considerado necessário, mas não suficiente para o entendimento dos mundos físico e social, por não ser capaz de estabelecer por si só as interações com os outros sistemas. Não dificilmente se encontra nos cursos pessoas aprendendo, de forma isolada, 
conteúdos isolados de matemática, em detrimento de ações coletivas ancoradas em práticas argumentativas - princípios basilares a ação comunicativa.

Neste sentido, a interdisciplinaridade, cujo princípio basilar também se assenta em pressupostos envolvendo coletividade, seria uma maneira de organizar e produzir conhecimento acerca da formação, buscando integrar as diferentes dimensões dos contextos sociais de atuação profissional. Com isso, uma prescrição curricular para educação profissional deve superar uma visão especializada e fragmentada do conhecimento em direção à compreensão da complexidade e da interdependência dos fenômenos sociais, prevendo para tal um espaço de diálogo, de troca, de discurso livre entre os docentes e alunos dos cursos.

Diante do exposto a integração da matemática com outras ciências, numa prática pedagógica e educacional, deveria assegurar o vislumbrar de um mundo menos fragmentado e mais articulado, com reais possibilidades de fazer uso de argumentos da ciência como elemento de interpretação e intervenção da realidade. Em consonância a isto, uma prática para ensino de matemática, na perspectiva da educação profissional, que faça adoção de uma proposta interdisciplinar, implicaria uma profunda mudança nos modos de ensinar e aprender, bem como na organização formal das instituições de formação profissionalizante, perpassando pela construção de novas metodologias, pela reestruturação dos temas e dos conteúdos curriculares, pela organização de equipes de professores que integrem diferentes áreas do saber e pelas possibilidades das instituições de ensino terem abertura para experimentar novas formas de organizar os profissionais, os currículos e os conteúdos, a estrutura formal da seriação (Carvalho, 1998).

Interdisciplinaridade no ensino de matemática em curso de formação para o mundo do trabalho requer reunião de pessoas, pois ela só se concretiza na coletividade, capazes de dialogar, com condições para e dispostas a isto. A interação entre os sujeitos é um pressuposto basilar para constituição de práticas interdisciplinares. A interação em espaços de diálogo não só é necessária para um posicionamento crítico em relação à sociedade contemporânea, mas amplia a atividade de labor cooperativo, fazendo a mediação entre as diversas áreas do conhecimento, entre a cultura sofisticada dos especialistas nas ciências e técnica e o mundo da vida.

Portanto, aqui se supõe, em primeiro lugar, a transformação de ações individuais de integração de conteúdos em postura coletiva de integração curricular; em seguida, num processo que possa ser caracterizado por cooperação interdisciplinar pautado por um agir comunicativo. O saber disciplinar declina de seu espaço de tribunal da razão técnica, para ser mediador, pautado na racionalidade comunicativa, um elo entre os 'experts das ciências e o mundo da vida cotidiana, nas relações com o mundo do trabalho.

\section{Considerações Finais}

Esperamos neste texto ter argumentado acerca das potencialidades da Teoria da Ação 
DOI: http://dx.doi.org/10.20396/zet.v24i3.8648089

Comunicativa de Habermas como referencial para discussões acerca interdisciplinaridade no ensino de matemática em currículos de educação profissional de nível técnico. Temos certeza que novos estudos na vertente aqui esboçada são necessários e trarão contribuições importantes a todos aqueles que lutam pela construção de uma educação profissional que não seja guiada, somente pelos imperativos sistêmicos, regidos pela burocracia, mas por processos comunicativos que prezem pela diversidade na participação e tomada de decisões nas relações com o mundo, nas relações com o trabalho e nas relações com o mundo do trabalho.

\section{Referências}

Adorno, T.(1996). Teoria da Semicultura. Educação e Sociedade, n. 56, p. 388-41.

Adorno, T.; Horkheimer, M.(1985). A dialética do Esclarecimento. São Paulo: Zahar.

Bauman, Z.(2008). Vida para consumo: a transformação das pessoas em mercadorias Tradução de Carlos Alberto Medeiros. Rio de janeiro: Zahar, 2008.

Brasil (2011). Sondagem especial da CNI. Brasília, Ano 9, n. 2. abr. 2011. Disponível em: $<$ http://www.abinee.org.br/informac/arquivos/sondabr.pdf >.

Brasil (2012a). Resolução CNE/CEB $n^{o}$ 02, de 30 de janeiro de 2012. Define diretrizes curriculares nacionais para o ensino médio. Brasília: CNE/CEB, 2012a.

Brasil (2012b). Resolução CNE/CEB $n^{\circ}$ 06, de 20 de setembro de 2012. Define diretrizes curriculares nacionais para a educação profissional técnica de nível médio. Brasília: CNE/CEB, 2012b.

Carvalho, I. C. M. (1998). Em direção ao mundo da vida: interdisciplinaridade e educação ambiental. Brasília: IPE - Instituto de Pesquisas Ecológicas.

D’Ambrosio, U. (2005). Sociedade, cultura, matemática e seu ensino. Educação e pesquisa, 1 (31), 99-120.

Fazenda, I. C. A (2008). Interdisciplinaridade-transdisciplinaridade: visões culturais e epistemológicas. In I.C.A. Fazenda (Org). O que é interdisciplinaridade?(pp 17-28) São Paulo: Cortez, 2008.

Fazenda, I. C. A. (2002). Interdisciplinaridade: um projeto em parceria. São Paulo: Edições Loyola.

Fazenda, I. C. A. (2011) Interdisciplinaridade: história, teoria e pesquisa. São Paulo: Papirus.

Fazenda, I. C. A. (2013). Práticas interdisciplinares na escola. $13^{\mathrm{a}}$ ed. rev. e ampl. São Paulo: Cortez.

Fazenda, I. C. A; Tavares, D. \& Godoy, H. (2015). Interdisciplinaridade na pesquisa científica. Campinas: Papirus.

Gentile, F.R. (2015). Interdisciplinaridade: a essência humana para a sustentabilidade da educação? Interdisciplinaridade, v.1, n.6, pp 37-43. 
Gonçalves, H. J. L. \& Pires, C. M. C. (2014) Educação matemática na educação profissional de nível médio: análise sobre possibilidades de abordagens interdisciplinares. Boletim de Educação Matemática (Bolema), v. 28, n. 48, pp230-254.

Gonçalves, H. J. L., Dias, A. L. B \& Peralta, D. A. P. (2015) O que dizem professores de uma instituição de educação profissional sobre interdisciplinaridade no ensino de matemática. Ciência \& Ensino, v. 04, n. 01, pp24-41.

Habermas, J. (1968). Técnica e Ciência como ideologia. Lisboa: Edições 70.

Habermas, J. (1984). Mudança estrutural na esfera pública: investigações quanto a uma categoria de sociedade burguesa. Rio de Janeiro: Novo Tempo.

Habermas, J. (1987). A nova intransparência: a crise do estado de bem estar social e o esgotamento das energias utópicas. Novos Estudos CEBRAP, n. 18, p. 103-114.

Habermas, J. (2001) Teoría de la Acción comunicativa I: racionalidad de la acción y racionalización social. $3^{\mathrm{a}}$ ed. Madri: Taurus.

Habermas, J. (2002). Acções, actos de fala, interacções lingüisticamente mediadas e o mundo vivo. In HABERMAS, Jürgen. Racionalidade e comunicação (pp 103-149). Lisboa: Edições 70.

Habermas, J. (2002). O discurso filosófico da modernidade. São Paulo: Martins Fontes.

Habermas, J. (2003). Teoría de la Acción comunicativa II: crítica de la razón funcionalista. $4^{\mathrm{a}}$ ed. Madri: Taurus.

Horkheimer, M. (1976). Eclipse da Razão. Rio de janeiro: Labor do Brasil.

Horkheimer, M.(1980). Teoria Tradicional e Teoria Crítica. Os Pensadores. São Paulo: Abril Cultural.

Japiassu, H. (1976). Interdisciplinaridade e patologia do saber. Rio de Janeiro: Imago.

Longhi, A. J. (2005). A ação educativa na perspectiva da teoria do agir comunicativo de Jürgen Habermas: uma abordagem reflexiva. Tese de doutorado, Universidade Estadual de Campinas, Campinas, SP, Brasil.

Machado, N. J. (2000). Educação: projeto e valores. São Paulo: Escrituras.

Mateus, L. (2016). A percepção interdisciplinar do aluno do curso técnico em enfermagem sobre cidadania. Interdisciplinaridade, v.1, n.8, pp 47-57.

Matos, O. (1989). Os arcanos do inteiramente outro: A escola de Frankfurt, a melancolia e a revolução. São Paulo: Brasiliense.

Medeiros, A. M. S. (2005). Formação de professores sob a perspectiva da teoria crítica e das políticas educacionais. Educação e Linguagem, ano 8, n. 11, p. 195-210.

Minayo, M. C. S. (1994). Interdisciplinaridade: Funcionalidade ou Utopia? Saúde e Sociedade, 3(2), pp42-64.

Miranda, P. R., Faria, R. C. \& Gazire, E. S. (2013). Interdisciplinaridade no ensino de matemática e educação física no PROEJA. Zetetiké: revista de educação matemática, 20 (38), pp111-124. 
DOI: http://dx.doi.org/10.20396/zet.v24i3.8648089

Mühl, E. H. (2003). Habermas: ação pedagógica como agir comunicativo. Passo Fundo: UPF.

Mühl, E.H.(1999). Racionalidade comunicativa e educação emancipadora. Tese de doutorado, Universidade Estadual de Campinas, Campinas, SP, Brasil.

Peterson, J. C. F. (2015). Desafios para a efetivação de um projeto interdisciplinar na contemporaneidade: Um diálogo com Jürgen Habermas e Ivani Fazenda. Interdisciplinaridade, v.1, n.6, pp 44-55.

Pires, C. M. C. (2004). Formulações basilares e reflexões sobre a inserção da matemática no currículo visando à superação do binômio máquina e produtividade. Educação matemática pesquisa, 6(2), pp29-61.

Prestes, N.H. (1995). A razão, a teoria crítica e educação. In Pucci, B. (Org). Teoria crítica e educação: a questão da formação cultural na Escola de Frankfurt. Petrópolis, RJ: Vozes.

Santomé, J. T. (1998) Globalização e interdisciplinaridade: o currículo integrado. Porto Alegre: Artes Médicas.

Sgró, M.(2007). Educação pós-filosofia da história: racionalidade e emancipação. San Paulo, SP: Cortez.

Tavares, D. E. (2014) Identidade. In: Fazenda, I. C. A. (Org.). Interdisciplinaridade: pensar, pesquisar e intervir. (pp. 135-139) São Paulo: Cortez.

Tedesco, J. C. (2004). O novo pacto educativo: educação, competitividade e cidadania na sociedade moderna. São Paulo: Ática.

Teodoro, A. (2003). É possível uma política de educação à esquerda? Uma reflexão sobre a possibilidade e esperança de acção política. Revista Lusófona da Educação, n.2, p. 4351.

Terradas, R. D. (2011). A importância da interdisciplinaridade na educação matemática. Revista da Faculdade de Educação, Ano IX, n. 16, pp 95-114.

Thiesen, J. S. (2008). A interdisciplinaridade como um movimento articulador no processo ensino-aprendizagem. Revista Brasileira de Educação [online], vol.13, n.39, pp.545554.

Tomaz, V. S. \& David, M. M. M. S. (2011) Interdisciplinaridade e aprendizagem da Matemática em sala de aula. Belo Horizonte: Autêntica. 